\title{
A Dynamic Diffusion of Mobile Phone in Korea: Focused on Traditional Marketing Activities and Online Word-of Mouth
}

\author{
Jieun Jeon*, Seong-hoon Gwon and Jaehyuk Cho \\ National Assembly Research Service, Seoul, Republic of Korea \\ National Assembly Research Service, Seoul, Republic of Korea \\ Korea Institute of S\&T Evaluation and Planning, Seoul, Republic of Korea \\ jejeon24@gmail.com,gwon@assembly.go.kr,cool@kistep.re.kr
}

\begin{abstract}
This paper examines the dynamic diffusion of mobile phones in Korea market, in which traditional marketing activities and online word-of-mouth play critical roles in influencing product sales. The focus of earlier studies was on understanding the effectiveness of marketing activities on product sales by limiting their studies to interaction among product sales, mass media, online word of mouth and the network structure of the market. In order to further refine this relationship, this paper provides an agent-based model to study dynamic diffusion pattern of mobile phone by considering their interactions and network structure.
\end{abstract}

Keywords: Product diffusion, Media marketing, Agent-based model

\section{Introduction}

The advent of mobile phones more than two decades ago made "anytime, anywhere" communication much easier between two people. A rapid adoption of this technology created a huge business opportunities for various manufacturing companies along the value chain. Many companies entered this market to seize this new business opportunities. As a result, this market has become very competitive. One area where a business manager needs to do well is in forecasting product sales to estimate the market size and understand a historical diffusion pattern of product.

Rogers[1] stated that key factors affecting the product or technology life cycle, adoption, and diffusion are communication channels, time, and social system. The communication channels are classified into mass media and interpersonal channels[1]. The mass media such as TV advertising, radio, newspaper and interpersonal channels can generate word of mouth. As the Internet technology evolved into a mainstream technology, online word-of-mouth on product information or reviews can have significant effect in instilling an opinion about the product in online community. Several studies showed the online word-of-mouth effect on product sales $[2,3,4,5]$ by examining the differences between word-of-mouth and online word-of-mouth [6]. However, their studies are limited to interactions of mass media, word-of-mouth, product sales, and network structure. Several approaches such as choice models [7] or neural networks [8] were used to forecast the consumer decision, but, there are limitations to using these mathematical approaches. Swait and Adamowicz [9] suggested that researchers should pay more attention to factors such as task complexity and context in modeling choice behavior. Midgley et al. [10] studied the relation between the diffusion of innovations and the network structure in that the communication links have a significant impact on the diffusion process. This suggests that there is a need to place a greater emphasis on a

Received (January 7, 2018), Review Result (March 19, 2018), Accepted (March 21, 2018)

${ }^{*}$ Corresponding Author 
dynamic interaction among product sales, mass media, and word-of-mouth in this research area.

This paper examines the dynamic diffusion of mobile phone in Korea market, in which traditional marketing activities and online word-of-mouth play critical roles in influencing product sales. We employ a three-prong approach for our study. First, we make a market system for mobile phones, consisting of mass media and interpersonal activity. Second, we attempt to identify a network structure of mobile market considering their dynamic interactions. Finally, we show simulation results of the dynamic diffusion pattern of mobile phones in the market. With this approach, we can identify the diffusion pattern in each market with different conditions.

The rest of this paper is organized as follows. Section 2 provides the theory background. In Section 3, we explain the agent-based model used in this study. Section 4 provides modeling concept. Our simulation results are analyzed and discussed in Section 5. Finally, Section 6 provides summary of our findings and implications of this research.

\section{Diffusion Theory}

Rogers[11] defined an innovation as "an idea, practice, or object that is perceived as new by an individual or other unit of adoption" and claimed that technological innovation is key factor leading to changes in product life cycle, adoption, and diffusion. However, once a technology or product is given, the main factors are communication channels, time, and social systems etc., [1]. The most important factor affecting new product selection and adoption is communication[12]. Rogers[1]classified the communication channels into mass media channels and interpersonal channels. And mass media such as an advertising plays a role like recognition of new product, ventilation of potential customers, and knowledge transfer of new product and interpersonal channels can be word or mouth and act to verify information, evaluate new product(indirect experience), and reduce the risk by accepting new product.

Since the 1960s, researchers conducted studies on the impact of product, service, or technology adoption by communication channels[12] In the past, researchers were interested in understanding the effect of mass media, such as TV advertising, radio, and newspaper, on product diffusion as marketing activities and word of mouth as the most important communication source between consumers [13]. Word-of-mouth was defined as information exchange process for products and services through interpersonal channels $[14,15,16]$. As Internet technology matured, we should consider the personal internet media which plays a role of word of mouth in online and there are several studies about the effect of online word of mouth on product sales [2, 3, 4, 5]. Although word of mouth has a great power to diffuse products in growth stage as considering the new product diffusion theory [17], several studies to date show the online word of mouth affect product sales in early stage of innovation process [6]. Unlike the information of the offline word of mouth, the information through online word of mouth is passed quickly to a wide range of consumers [2]. Bussiere [3] and Chatterjee [4] said that word of mouth has been widespread due to popularization of the Internet and the impact of online word of mouth is even greater to consumer information search and purchasing decisions than that of the past offline word of mouth. Godes and Mayzline [18] said the information makes it to be able to track, copy, and analyze word of mouth content because the information is form in written format in Internet. Using reviews for two Internet bookstores(Amazon, Barnes \& Noble), Chevailer and Mayzlin [5] studied the effect of online word of mouth to book sales. They also said that online could be utilized as Internet marketing means anonymously and it would be efficient than traditional marketing techniques. Huang et al., [19] experiemented that the characteristics of word of mouth such as quality, authority, authenticity, and interestingness make some effect on resenders' acceptance toward word of mouth positively, which can be called ripple effect. Cui et al., [20] examined the effect 
of online reviews on new product sales for consumer electronics video games depending the reviews' volume, valence, dispersion and found that the volume of reviews affected new product sales in the early stage of diffusion process.

As described in the aforementioned studies, researchers have argued that the online community should exchange the product's information and generate word-of-mouth for good marketing place [21, 22]. Andersen [21] shows that online community which is deliberately structured by companies in the context of B2C as well as in the context of B2B can be an effective means of communication for relationship marketing. Elliott[22] argues that customer community is core infrastructure of online word of mouth activation, which means community acts as facilitating the interaction between the customer and, because of this, the effect of adoption and diffusion increases rapidly by word of mouth. C. Song and J. Shin[23] claimed that interactivity should be considered an important characteristic for Internet marketing in that enhance interactivity by making internet personal interaction between consumers and business more efficient in terms of marketing. Sundaram and Taylor[24] said that uncertainty related to purchase enhances browsing activities about information. Online word-of-mouth mainly occurs actively through comments on the Internet bulletin boards and the trend is moving from café/club communities to blogs, homepage, and other personal media such as facebook and instagram. In this point, this study uses the online article as online word of mouth.

\section{Agent-Based Model}

In an agent-based model(ABM), agents are heterogeneous individuals, acting with unique rule in decision-making. Specifically, agents act and interact repeatedly in a dynamic environment. This creates an evolving system that affects the innovation process. ABM's main goal is to construct theory, not to make an accurate and predictive model. This model differs from other simulation approaches in several areas. First, ABM agents are heterogeneous and act with each other in their environment unlike the other models where the agents are homogeneous and are behaving individually at the average level. Second, unlike the other models, ABM allows the agents to adapt at their own pace and unique way. Finally, a behavior rules are different compared with other simulation methods. The agents act depending on the behavior rules set by researchers. The rules can make the system slowly to become more complex incrementally. ABM provides flexibility to simulate direct or indirect interactions dynamically between entities coexisting in a cohesive environment.

$\mathrm{ABM}$ has several advantages. ABM purposes to show how process evolves over time and how the system can be changed by rules. The model can make intuition for arranging theories. And ABM's benefit is that the model can be used in a system in which the unit of agent is the individual such as consumer and firm and the micro behavior and macro pattern are focused on. It can be applied to adoption and diffusion innovations. In ABM, the patterns are replicated, which create the dynamic environments in which individuals enter and exit the system. The concept of emergence cannot be ignored in ABM. The model is important for dynamic systems which create emergence[25] and coevolving systems. In emergent systems, the entire system is greater than the sum of parts[25]. In economics field, the emergence is generated by the interaction of agents and then, growing economies, which can be called agent-based computational economics[26]. The model is also applied when agents act as form of nonlinear. If agents represent memory, path-dependence, hysteresis, non-Markovian behavior, or temporal correlations, ABM can be used and stochastic process can be modeled as agents' behavior. Another advantage is important for this research. ABM distinguishes between physical space and temporal space and it makes social network of diffusion modeled. Barabasi[27], Valente[28] and Watts and Stogatz[29] have been interested in the study of social networks. Watts and Stogatz[29] showed local and global dynamics are affected by the 
network's structure. Garcia et al., [30] also examined the effect of social network on the rate of diffusion in different types including a random network, a cellular automata network, a small-world network, and a scale-free network and identified that small-world networks can be useful for the diffusion of the innovation in high uncertainty of performance.

Aforementioned advantages generated great interests in ABM as it was applied to model insect behavior, urban systems, traffic-flow dynamics, and civil violence [31]. In addition, it has been widely used for innovation diffusion research [32, 33].

To conduct ABM research, there are several steps. The initial step is to set up research questions by a researcher. After this initial step, the researcher should proceed with the following steps. First, theory should be operationalized through a cognitive map creation. Second, agent and environment should be specified. Finally, the behavior rules should be established as well as measurement procedure, data collection, and run-time. These steps need not to be in sequential order. In the next section, we propose an agent-based model for this study.

\section{Modeling Concept}

\subsection{Agents}

In this study, agents are heterogeneous consumers and interact with each other in a market where TV advertising and online word of mouth coexist. They have their own preference to a certain product. And they are affected by external environment and act depending on those conditions. The external environment and online word of mouth that are identified to affect consumer's purchase decision. Since price factor is the important to make for consumers to purchase, we determine the price is control factor for this system. We assume there are 500 consumers in a market and they form a network relation in the market when TV advertising and online word of mouth exist together.

\subsection{Decision process}

In order to construct decision-making process, we consider intrinsic preference, price, and TV advertising and online word of mouth exposure as effective factors. First, we set up that consumers have their own intrinsic preference, which means consumers prefer certain product such as its brand and attributes. It doesn't change with any conditions. Therefore, we set the decision process as both normal and uniform distribution. Price is important factor to influence purchase behavior of potential consumers[34]. Previous research attempted to show the relationship between price and customers' purchase decisions as dividing into objective and reference price[35, 36]. As a control factor, price distributed pattern can be classified into two patterns, uniform distributed pattern and reexponential pattern. Price strategy depends on company's strategy direction and we interviewed an employment to ask the strategy. Even though we haven't obtained real data to plot the price change pattern, we got the information that mobile manufacturing company has two strategies roughly. One strategy is for premium phones. It tends not to change the phone's price and continue to maintain initial price when products are released in a market. This pattern would be uniform distributed pattern. The other strategy is for general phones. This type is decreasing as the products are diffusing in the market over time. The dynamic pattern of the price can be formed as re-exponential distributed pattern. In this product type, the price is affected by market conditions and, in general, the pattern of the price would be decreasing after entering the market. Even though there are several factors to affect the change of price, since we are focused on the marketing activities in this research, we should consider only the dynamic pattern of price.

As aiming to construct a market system, we consider two marketing activities, mass media and online word of mouth. Previous research represented the mobile phone 
companies' TV advertising distributed pattern as log-normal distributed pattern [37]. The distributed pattern is not for mobile manufacturing company but for mobile service company. But, in Korea, mobile service companies are related closely to manufacturing companies and, in mobile service TV advertising, certain product of manufacturing company can be exposure. In Korea mobile market, manufacturing company decides to release their product with particular companies and mobile service company use certain product in their TV advertising. For example, Apple contracted with only KT, one of the mobile service companies, when they enter the Korea market and KT used iPhone for their TV advertising when iphone was launched in Korea. Therefore, the mobile service advertising pattern can be substituted for mobile phone advertising. The other marketing factor is online word of mouth. The distributed pattern got obtained from real data of 10 mobile phones in Korea and the information or reviews for the products were tracked by web-text mining. We gathered the article monthly and count the number of article in the month. The article life time follows the period of product life time and several phones' article in online lasted more than one or two months than product life time in market. The distributed pattern can be shown as gamma distributed pattern and the pattern can be classified into the peak point in early time and mid-time. In this research, we assume online WOM affects early stage of innovation process according to Dellarocas et al., [6]. As above-mentioned decision rules, Table 1 shows a summary of decision rules.

Table 1. Summary of Decision Rules

\begin{tabular}{lcc}
\hline \multicolumn{1}{c}{ Factor } & Distributed pattern & Formula \\
\hline $\begin{array}{l}\text { Intrinsic } \\
\text { preference }\end{array}$ & Uniform / Normal distributed pattern & $\frac{1}{(b-a)} \frac{1}{\sigma \sqrt{2 \pi}} e^{-\frac{(\alpha-u)^{2}}{2 \sigma^{2}}}$ \\
\hline Price & $\begin{array}{c}\text { Uniform distributed pattern(premium } \\
\text { phone) }\end{array}$ & $\frac{1}{(b-a)}$ \\
\cline { 2 - 3 } & $\begin{array}{c}\text { Re-exponential distributed } \\
\text { pattern(general phone) }\end{array}$ & $\frac{1}{\lambda e^{-\lambda x}}$ \\
TV advertising & Log-normal distributed pattern & $i<j$, \\
\hline $\begin{array}{l}\text { Online word of } \\
\text { mouth }\end{array}$ & Gamma / Exponential distributed pattern & $\left.\frac{1}{\theta^{k} \Gamma(k)} x^{-\frac{(x-u)^{2}}{2 \sigma^{2}}}\right)$ \\
\hline
\end{tabular}

The final adoption can be determined by generalized bass model. Bass model represents product diffusion model which some individuals decide to adopt an innovation independently of the decisions of other individuals in a social system[17]. The equation form follows.

$$
L(t)=\frac{f(t)}{1-F(t)}=p+\frac{q}{N} N(t)
$$

In this equation, $N_{(t)}$ represents the number of customers who have already adopted the innovation by time $\mathrm{t}$ and $\bar{N}$ is a parameter representing the total number of customers in the adopting target segment. $p$ is coefficient of innovation and ${ }_{q}$ is coefficient of imitation and ${ }_{Y(T)}$ is the previous buyers. And Bass, Krishnan, and Jain[38] suggested a general form of Eq.(1) as considering the effects of marketing-mix variables on the likelihood of adoption and the equation form as follows. 


$$
\begin{aligned}
& f(t)=\left[p+\frac{q}{\bar{N}} N(t)\right][1-F(t)] x(t) \\
& x(t)=1+\alpha \frac{[P(t)-P(t-1)]}{P(t-1)}+\beta M a x\left\{0, \frac{[A(t)-A(t-1)]}{A(t-1)}\right\}
\end{aligned}
$$

Thus, in this study, we use generalized bass model because the model considers the marketing activities. $p$ can be considered as intrinsic preference and the adoption equation can be formed as follows for this study.

$$
\text { Adoption }=\text { Intrinsic preference }+ \text { price }+ \text { TV advertising }+ \text { online word of mouth }
$$

\section{Simulation and Results}

We constructed a market system based on an agent-based model, using the Netlogo software developed by Northwestern University. This software provides tools to easily construct a model with agents and behavior rules. In this section, we present the modelproduced dynamic pattern of mobile phone purchase.

First, considering intrinsic preference, there are two categories of product purchasers: early adopter and general consumer. As shown in Figure 1, early adopters tend to buy the product once it is launched. They wait for one or two month and the customers' purchasing pattern is increasing, peaking, and descending over time. For the customers of general category, there is no change in the consumption pattern. They are not affected by any factor in the market and are characterized by their utilitarian motive in buying a phone and focusing only on its basic features. Especially, both of two consumer categories are not affected by the premium price strategy.

Second, the pricing strategy is meaningful. The price factor affects the sales of a product for a short time in the early adopter category. The pattern shows higher sales during the early phases than during later ones. In addition, for general consumer, it changes over time. The purchase of the product by general consumers changes over time although the change is not dramatic. That shows that the price sensitivity over time depends on consumer types as shown in Figure 2. We consider TV advertising as the traditional marketing strategy. As TV advertising activity starts, the pattern widens, regardless of customer type. Even though the pattern is maintained like the pattern that we consider both the intrinsic preference and price, we see the wider pattern. We can say that consumers purchase the product earlier if they are exposed to TV advertising. We can see the results in Figure 3.

Finally, we can see the dramatic change when online marketing is considered. By considering two decision rules of online marketing, exponential and gamma distribution, four patterns are obtained as shown Figure 4. First, when the online marketing has an exponential pattern, it is wider than the pattern with pricing and TV advertising factors, regardless of consumer types. This means that if we employ all the marketing strategies, it makes consumers purchase products more quickly. Especially, for general consumers, they do not buy the product as soon as it is launched, but tend to buy it when they are exposed on online advertising. In addition, if the online marketing shows gamma distribution pattern, sales volume show a sharp increase after a certain period of time. It also leads to a higher total sales volume than any other situation. Comparing these results, TV advertising and online marketing are found to be more effective for short-term sales than the pricing strategy, as indicated by the wider pattern. It also leads to the conclusion that we should consider online marketing at the early stage of product sale. 


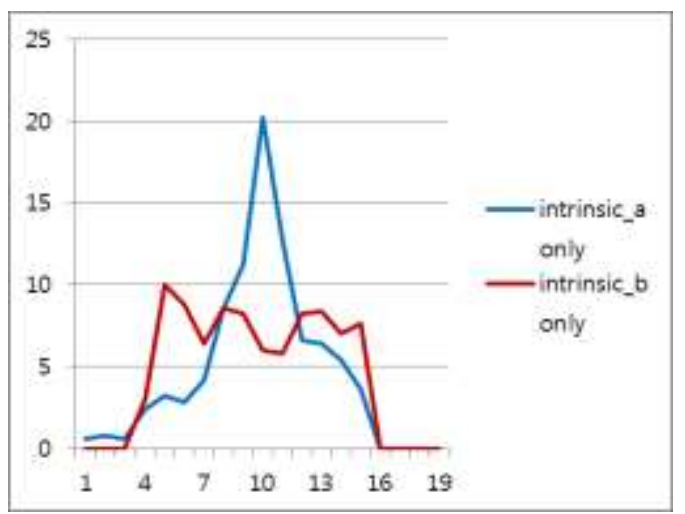

Figure 1. The Result of Simulation considering Intrinsic Preference Only

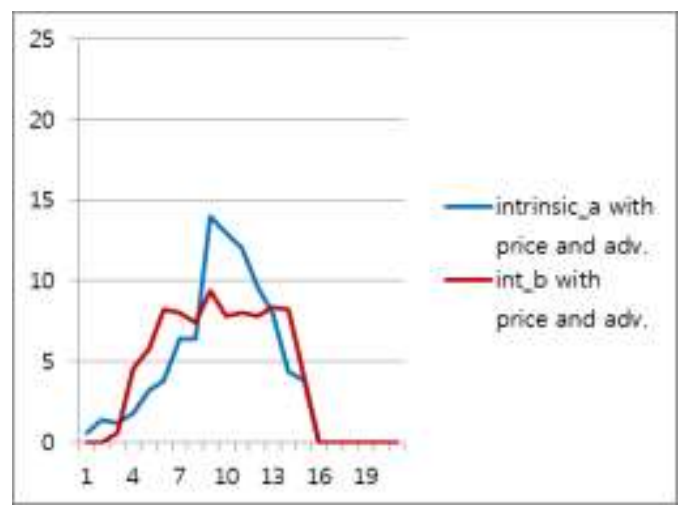

Figure 3. The Result of Simulation considering Intrinsic Preference with Price and TV

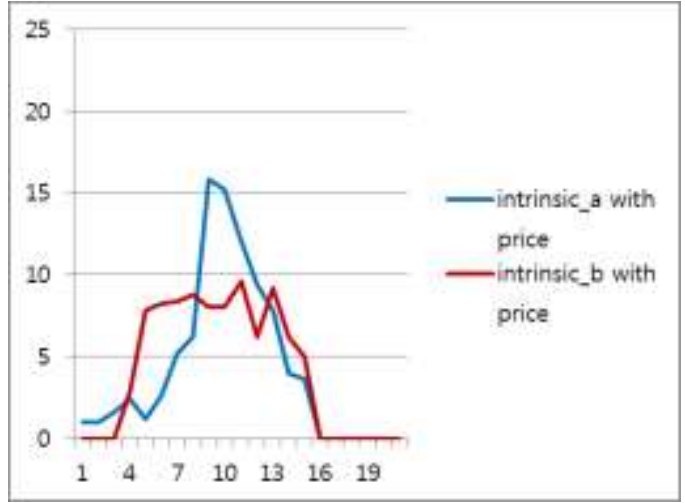

Figure 2. The Result of Simulation considering Intrinsic Preference with Price



Figure 4. The Result of Simulation considering Intrinsic Preference with All Strategies

Note: Intrinsic preference (a) represents early adopter (uniform distribution) and Intrinsic preference (b) represents general consumer (normal distribution). Price represents the firm's price strategy for the product. Adv means TV advertising. Online (a) represents exponential pattern of online marketing and Online (b) the gamma pattern of online marketing.

\section{Discussion and Conclusions}

As technology innovation speeds up, creative ideas and strategies become more important. This study examines the effects of corporate marketing strategies on product proliferation and simulates the complex systems using an Agent-based model. In particular, we consider online marketing strategies, such as user feedback on new media, because of the development of the Internet. This research makes contributions to the development of product diffusion patterns by considering complex, new marketing activities required in recent.

First, the system was constructed according to the conditional changes in various scenarios (various marketing strategy options in this study). When various marketing strategies act simultaneously in a system, it will be possible to forecast the future patterns by applying the complex system in the future and looking at the system change over time. The purpose of the prediction proposed in this study is not to predict the cumulative sales volume at a specific point of time in the future. The value of the specific point in time is presented in the application of methodology; however, rather than paying attention to these numbers, it is more appropriate to examine how the value of a point in time varies 
conditionally under various scenarios. By looking at the future changes in strategy, we can consider the cost and effect of the strategy of the company, and this makes it possible to select the desired scenario among the various options.

Second, we apply the simulation method to the innovation research. That is, we study the diffusion pattern structure of the product through an agent-based model, which is a simulation. Agent-based model simulation bas been used for organizational change and urban planning due to individual behavior change. Recently, there are more and more cases of this model being used in economics and technology management. In this study, it is possible to look at the changes of the whole system by changing one factor and by constructing a more stereoscopic and structural model; thus, we deviate from the dependence on statistical model to see the product diffusion pattern as the technology prediction model. It is expected that this will enable the decision makers of the enterprise to establish specific strategies.

Finally, it contributes to the theoretical development by applying this methodology. The innovation diffusion theory discussed in this study is based on the idea that the individual or decision-making unit is a process of diffusion until the acceptance of innovation. It is a micro- and the macro- in process in which the potential customer decides whether to accept it or rejects it. It is difficult to simultaneously express these microscopic and macroscopic processes, so we can only confirm the empirical results from one aspect, that is, micro or macro aspect. However, in order to verify the theory accurately, two aspects need to be examined at the same time, and this study makes it possible by applying the new methodology. Agent-based model is a bottom-up model that focuses on the emergence of macroscopic patterns that occur because of microinteractions. Therefore, agent-based model is a suitable alternative to solve a problem that diffusion theory is a collective phenomenon caused by decentralized individual decision makers and it is not easily analyzed by the traditional quantitative or qualitative approach.

\section{References}

[1] E. M. Roger, "Diffusion of Innovation(5 $5^{\text {th }}$ ed)", Free Press, New York, (2003).

[2] S. Kiesler, "Culture of the Internet(Ed.)", NJ:Lwarence Erbaum Associates, Mahwah, (1997).

[3] D. Bussiere, "Evidence and Implications of Electronic Word of Mouth", Proceeding of the Annual Conference of the Academy of Marketing Science, (2000).

[4] P. Chatterjee, “Online Consumer Reviews: Do Consumers Use Them?”, 2000 Association of Consumer Research Annual Conference, Salt Lake City, UT, (2000).

[5] J. A. Chevalier and D. Mayzlin, "The Effect of Word of Mouth on Sales: Online Book Reviews", Journal of Marketing Research, vol. 43, no. 3, (2006), pp. 345-354.

[6] C. Dellarocas, X. Zhang and F. W. Neveen, "Exploring the Value of Online Product Reviews in Forecasting Sales: The Case of Motion Pictures", Journal of Interactive Marketing, vol. 21, (2007), pp. 23-45.

[7] P. K. Chintagunta, "Variety Seeking, Purchase Timing, and the "Lightning Bolt" Brand Choice Model", Management Science, vol. 45, no. 4, (1999), pp.486-498.

[8] C. Gan, V. Limsombunchao, M. D. Clemes and Y. Y Weng, "Consumer Choice Prediction: Artificial Neural Networks versus Logistic Models", (2005).

[9] J. Swait and W. Adamowicz, "Choice Environment, Market Complexity, and Consumer Behavior: A Theoretical and Empirical Approach for Incorporating Decision Complexity into Models of Consumer Choice", Organizational Behavior and Human Decision Processes, vol. 86, no. 2, (2001), pp. 141-167.

[10] D. F. Midgley, P. D. Morrison, J. H. Roberts, "The Effect of Network Structure in Industrial Diffusion Processes", Research Policy, vol. 21, no. 6, (1992), pp. 533-552.

[11] E. M. Roger, "Diffusion of Innovation( $3^{\text {rd }}$ ed)", Free Press, New York, (1983).

[12] Y. Chen and J. Xie, "Online Consumer Review: Word-of-Mouth as a New Element of Marketing Communication Mix", Management Science, vol. 54, no. 3, (2005), pp. 477-791.

[13] C. Derbaix and J. Vanhamme, "Inducing Word-of-Mouth by Eliciting Surprise-A Pilot Investigation", Journal of Economic Psychology, vol. 24, no. 1, (2003), pp. 99-116.

[14] J. Arndt, "Role of Product-Related Conversations in the Diffusion of an New Product", Journal of Marketing Research, vol. 4, (1967), pp.291-295.

[15] R. A. Westbrook, "Product/Consumption-based Affective Responses and Postpurchase Processes", Journal of Marketing Research, vol. 24, no. 3, (1987), pp. 258-270. 
[16] W. J. Carl, "What's All the Buzz about? Everyday Communication and the Relational Basis of Word-ofMouth and Buzz Marketing Practices", Management Communication Quarterly, vol., 19, no. 4, (2006), pp. 601-634.

[17] F. M. Bass, “A New Product Growth for Model Consumer Durables”, Management Science, vol. 15, no. 5, (1969), pp. 215-227.

[18] D. Godes and D. Mayzlin, "Using Online Conversations to Study Word-of-Mouth Communication", Marketing Science, vol. 23, no. 4, (2002), pp. 545-560.

[19] M. Huang, F. Cai and A. S. L. Tsang, "Making Your Online Voice Loud: the Critical Role of WOM Information", European Journal of Marketing, vol. 45, no. 7/8, (2011), pp. 1277-1297.

[20] G. Cui, H. K. Lui, and X. Guo, "The Effect of Online Consumer Reviews on New Product Sales", International Journal of Electronic Commerce, vol. 17, no. 1, (2012), pp. 39-58.

[21] P. H. Andersen, "Relationship Marketing and Brand Involvement of Professionals through WebEnhanced Brand Communities: The Case of Coloplast", Industrial Marketing Management, vol. 34, no. 3, (2005), pp. 285-297.

[22] K. M. Elliott, "Understanding Consumer-to-Consumer Influence on the Web", PhD Thesis, Duke University, Durham, NC. (2002).

[23] C. S. Song and J. C. Shin, "Building Interactivity of the Internet", Marketing Research, vol. 14, no.3, (1999), pp. 69-95.

[24] D. S. Sundaram, R. D. Taylor, "An Investigation of External Information Search Effort" Replication in In-Homo Shopping Situations", in NA-Advances in Consumer Research, vol. 25, eds. Joseph W. Alba \& J. Wesley Hutchinson, Provo, UT" Association for Consumer Research, (1998) pp. 440-445.

[25] J. H. Holland, "Emergence: From Chaos to Order". MA: Perseus Books, Cambridge, (1998).

[26] L. Tesfatsion, "Agent-Based Computational Economics: Growing Economies from the Bottom Up", Artificial Life vol. 8, no. 1, (2002), pp. 55-82.

[27] R. Albert and A. L. Barabasi, "Statistical Methods of Complex Networks", Reviews of Modern Physics vol. 74, no. 1, (2002), pp. 47-97.

[28] T. W. Valente, "Network of Models of Diffusion of Innovation", NJ: Hampton Press, Cresskill, (1995).

[29] D. J. Watts and S. J. Strogatz, "Collective Dynamics of 'Small-World' Networks", Nature, vol. 393, (1998), pp. 440-442.

[30] R. Garcia, R. Calantone, and R. Levin, "The Role of Knowledge in Resource Allocation to Exploration versus Exploitation in Technologically Oriented Organization”, Decision Science vol. 34, no. 2, (2003), pp. 323-349.

[31] J. Rauch, "Seeing around Corners", Atlantic Monthly vol. 298, (2002), pp. 35-48.

[32] S. A. Delre, W. Jager, T. H. A. Bijmolt, M. A. Janssen, "Targeting and Timing Promotional Activities: And Agent-Based Model for the Takeoff of New Products", Journal of Business Research, vol. 60, no. 8, (2007), pp. 826-835.

[33] J. D. Bohlmann, J. C. Roger, and M. Zhao, "The Effects of Market Network Heterogeneity on Innovation Diffusion: An Agent-Based Modeling Approach", Product Innovation Management, vol. 27, no. 5, (2010), pp. 741-760.

[34] T. Z. Chang and A. R. Wildt, "Price, Product Information, and Purchase Intention: An Empirical Study", Journal of the Academy of Marketing Science, vol. 22, no. 1, (1994), pp. 16-27.

[35] C. W. Sherif, "Social Categorization as a Function of Latitude of Acceptance and Series Range", Journal of Abnormal and Social Psychology, vol. 67, no. 2, (1963), pp. 148-156.

[36] K. B. Monroe and R. Krishnan, "The Effect of Price on Subjective Product Evaluations", InPerceived Quality, Eds. Jacob Jacoby and Jerry Olson, MA”, Lexington Book, Lexignton, (1985).

[37] S. Y. Sohn and H. Choi, "Analysis of Advertising Lifetime for Mobile Phone", Omega, vol. 29, no. 6, (2001), pp.473-478.

[38] F. M. Bass, T. V. Krishnan, D. C. Jain, "Why the Bass Model Fits without Decision Variables", Marketing Science, vol.13, no.3, (1994).

\section{Authors}

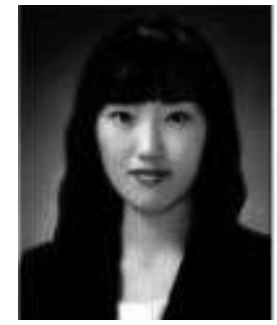

Jieun Jeon is a legislative researcher at the Science, Media \& Telecommunications Team, National Assembly Research Service, Republic of Korea, where she conducts research in the science, technology and innovation policies. She has studied about innovation and technology management. 


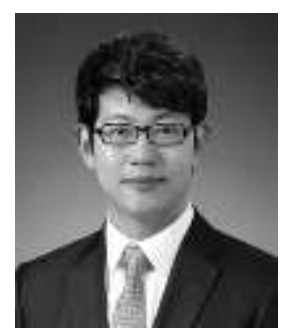

Seong-hoon Gwon is a legislative researcher at the Science, Media \& Telecommunications Team, National Assembly Research Service, Republic of Korea, where he conducts research in the science, technology and innovation policies.

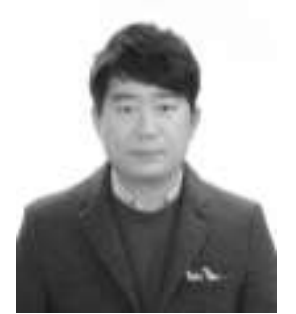

JaeHyuk Cho received Ph.D. in Computer Science, focusing on Mobile \& Embedded computing Systems at Chung-Ang University in South Korea. $\mathrm{He}$ is currently working as a national $R \& D$ program project manager at the Korea Institute of S\&T Evaluation and Planning (KISTEP). His research interests include IoT (Internet of Things), Smart City (U-City), SW Platform System (Vehicle \& Ship, etc.) and Embedded System. 